\title{
EL 'RELATO DE VIAJES': HITOS Y FORMAS EN LA EVOLUCIÓN DEL GÉNERO
}

\author{
LUIS AlbuRQUERQUE-GARCÍA \\ CCHS-CSIC
}

\section{RESUMEN}

El 'relato de viajes' se perfila como un marbete caracterizador de un género con unos rasgos comunes a lo largo de la historia, a pesar de los diferentes moldes que asume según los períodos y las corrientes en que se inserta. Se trata de mostrar cuáles han sido las obras que han actuado como hitos en la evolución del género. A su vez, se apunta la relación dialéctica entre el género y algunos paradigmas culturales, cuyas huellas se pueden rastrear en aquel. Las crónicas de indias, por ejemplo, llevan el marchamo renacentista. Por su parte, el giro ilustrado y el sesgo romántico graban su impronta en el género con un afianzamiento del docere y una ampliación de los moldes genéricos en el primero (memorias, epistolarios, crónicas) y una conversión de la voz del autor en instancia decisiva, en el segundo. En suma, el 'relato de viajes' ha pervivido a través del tiempo amoldándose a los numerosos avatares históricos culturales. Quizá por eso se le ha calificado como híbrido, interdisciplinar y con una notable capacidad para metamorfosearse.

Palabras clave: literatura de viajes, relatos de viajes, género.

\section{'TRAVEL NARRATIVE': LANDMARKS AND FORMS IN THE EVOLUTION OF THE GENRE}

\begin{abstract}
'Travel narrative' has become the characterizing label of a genre that has maintained certain common features throughout history, despite the different molds it has had to adapt to depending on the periods and movements it finds itself in. The idea is to show what works have served as landmarks in its evolution, as well as to highlight the dialectic relationship between the genre and several cultural paradigms whose tracks can be traced within it. The chronicles of the Indies, for example, bear a Renaissance stamp. Additionally, the Enlightened twist and Romantic turn leave their mark on the genre in the establishment of the docere and an expansion of the genre molds in the case of the former (memoirs, collected letters, chronicles) and a conversion of the author's voice as a decisive moment in the latter. All in all, 'travel narrative' has survived over time by adapting to different historical and cultural changes. Perhaps that is why it has been deemed a hybrid, interdisciplinary and with a notable ability to metamorphosize.
\end{abstract}

Key words: travel literature, travel narrative, genre. 
Hace ya unos años publiqué el artículo «Los libros de viajes como género literario» en el que reflexionaba sobre algunos aspectos teóricos en relación con la literatura de viajes. Quisiera ahora hacer, teniendo en cuenta lo escrito desde entonces sobre la materia apodémica, una segunda aproximación al género tratando de ilustrar los aspectos teóricos en su evolución a lo largo de la historia. Se trata, por una parte, de repensar y sistematizar lo ya dicho y, por otra, al contrastarlo con ejemplos procedentes de nuestra tradición literaria en diferentes períodos, de presentar una más aquilitada teoría del género. De ahí que aluda o vuelva en ocasiones a ideas o temas de trabajos previos pues, al tratarse de una visión de conjunto, es casi imposible no aprovecharlos integrándolos dentro de la exposición.

\section{TEORÍA DEL GÉNERO}

No es una novedad afirmar que el viaje ha presidido los grandes relatos de la humanidad. Partes importantes de la Biblia o La Odisea, sin ir más lejos, se vertebran en torno a un viaje. Pero aún más. El viaje y su relato no han dejado de tener una presencia constante a lo largo de la historia. Como ya he dicho en alguna otra ocasión, viaje y vida son, en cierto sentido, sinónimos, ya que su fuente y raíz se encuentra en el desplazamiento mismo. Teniendo en cuenta estas dos premisas (su amplitud y su secular pervivencia) se podría empezar sugiriendo que la literatura de viajes recorre toda la historia (o gran parte de la historia) y que el viaje forma parte de la condición humana, pero no sólo como producto de la curiosidad, sino como verdadera necesidad vital.

Según esto, sus límites como género serían tan abarcadores que casi se solaparían con la literatura misma. No soy el primero en sostener, por tanto, que la mayoría de las grandes obras de la literatura universal son libros de viaje. La Eneida, la Divina Comedia, el Quijote... Se hace necesario discernir el género 'relato de viajes', sintagma acuñado con un sentido muy preciso por Carrizo Rueda (1997), de la literatura de viajes en general.

Los 'relatos de viajes' responden a mi entender a tres rasgos fundamentales que se complementan con algunos más que luego veremos: (1) son relatos factuales, en los que (2) la modalidad descriptiva se impone a la narrativa y (3) en cuyo balance entre lo objetivo y lo subjetivo tienden a decantarse del lado del primero, más en consonancia, en principio, con su carácter testimonial.

(1) Recordemos que la distinción de Genette (1993: 53-76) entre relatos factuales y ficcionales facilitaba la consideración de literarios a ciertos textos hasta entonces exiliados de aquel ámbito. Relatos historiográficos, biografías, diarios, memorias y, por supuesto, relatos de viaje (aunque no fueran expresamente citados en aquella relación), entre otros, componen un friso de textos cuyo denominador común es su factualidad. Se asientan en los hechos, en 
la realidad, en los testimonios, en lo verificable. Lo ficcional no adquiere forma sustantiva en estos textos, sino más bien adjetiva. No es lo mismo, pues, un relato anclado en un hecho real (en un viaje concreto, sin ir más lejos), aunque sometido a un cierto grado de ficcionalización, que un texto ficticio que arranca de un hecho real o se nutre de experiencias personales. El relato factual nace, se desarrolla y termina siguiendo el hilo de unos hechos realmente acaecidos que forman su columna vertebral. El relato de ficción, por su parte, se toma siempre como una invención del que lo cuenta o de algún otro de quien la hereda. Lo que no obsta para que - como apunta Genette- «un historiador invente un detalle $\mathrm{u}$ ordene una intriga o que un novelista se inspire en un suceso; lo que cuenta en este caso es el estatuto oficial del texto y su horizonte de lectura» (1993: 55). La factualidad de estos relatos, cuyo componente cronológico y topográfico remite a un tiempo y un espacio vividos por el viajero, no excluye su condición de literarios. (Como vemos, el concepto de 'literariedad', a saber, qué hace que un texto sea o no literario, nos sale al paso de una manera u otra en cualquier reflexión teórica).

(2) El predominio en estos relatos de la descripción sobre la narración supone que aquélla actúa como configuradora de un discurso que no aboca hacia el desenlace propio de las narraciones. El discurso se represa en la travesía, en los lugares, y en todo lo circundante (personas, situaciones, costumbres, leyendas, mitos, etc.), que se convierten en el nervio mismo del relato. Añadiremos, parafraseando a Raúl Dorra (1983), que el factor «riesgo» que caracteriza lo específicamente narrativo y que mira siempre hacia el desenlace, aparece en estos 'relatos de viajes' engullido por el propio recorrido y el mundo que le sirve de escenario. En definitiva, las representaciones de objetos y personajes, que constituyen el núcleo de la descripción, asumen el protagonismo del relato, desplazando por consiguiente a la narración de su secular lugar de privilegio ${ }^{1}$.

Todo el cortejo de figuras retóricas que determinan el género se articulan en torno a la descripción o écfrasis, entendida como mecanismo que busca «poner ante los ojos» la realidad representada. Aludiremos solo de pasada a figuras como la prosografía (descripción del físico de las personas), la etopeya (descripción de las personas por su carácter y costumbres), la cronografía (descripción de tiempos), la topografía (descripción de lugares), la pragmatografía (descripción de objetos, sucesos o acciones), la hipotiposis (descripción de cosas abstractas mediante lo concreto y perceptible), etc. Es claro que se podrían seleccionar también figuras importantes como, por ejemplo, los tropos (metáforas, metonimias, sinécdoques, etc.) pero hemos referido solo aquéllas que se decantan hacia lo descriptivo como eje vertebrador del relato ${ }^{2}$.

\footnotetext{
1 Véanse al respecto las reflexiones de Carrizo Rueda (1997: 13-34).

${ }^{2}$ Una de las más completas clasificaciones de figuras retóricas puede verse en García Barrientos (1998).
} 
(3) El carácter testimonial, por último, interviene como otro rasgo fundamental del género 'relato de viajes'. Por un lado, dice de la objetividad de lo que se ha vivido (y recorrido), por otro, dice de la cercanía y del compromiso con lo que se narra lo cual, inevitablemente, nos acerca al carácter parcial de lo relatado, pese a la ecuanimidad de que se procura revestir. El testimonio que, sin duda, apunta hacia la objetividad, en ocasiones se inclinará hacia lo subjetivo, como veremos en los 'relatos de viajes' del siglo XIX, que supusieron un giro radical en la concepción del género como consecuencia del cambio de paradigma cultural: la lámpara, metáfora del romanticismo, sustituye al espejo (neoclasicismo), según la famosa acuñación de Abrams en su libro sobre teoría del romanticismo.

Recapitulando, el campo del 'relato de viajes' restringe necesariamente sus límites abrazando los relatos estrictamente factuales. Cabe decir que, si bien todo libro de viajes se enmarca dentro del ámbito de la literatura de viajes, no toda literatura de viajes queda incluida dentro de los 'relatos de viajes'. A la literatura de viajes se adscribirían obras en las que el viaje forma parte del tema o en las que actúa como motivo literario. Como ya he advertido en otras ocasiones, una epopeya, una comedia, una novela o un relato breve, por ejemplo, en cuyo esquema narrativo intervenga un viaje (en forma de peregrinación, de expedición, de travesía, etc.), tiende a clasificarse en la categoría general de libro o literatura de viajes. Pero, insisto, corremos el peligro de confundir el contenido de un marbete tan amplio con el de la literatura misma. ¿Acaso el famoso Viaje alrededor de mi habitación que escribió Xavier de Maistre a finales del XVIII, no podría considerarse un libro de viajes con todo rigor?

De estos tres aspectos configuradores del 'relato de viajes' se derivan otros que apuntalan, me parece a mí, la índole del género. Me refiero a la paratextualidad y a la intertextualidad. La primera actúa como ingrediente natural de estos relatos y no como mera excrecencia derivada de su condición factual. Los propios títulos de los libros, los encabezamientos e íncipit de los capítulos, los prólogos, o las mismas ilustraciones componen el mosaico de las manifestaciones más conocidas del procedimiento que, como marcas paratextuales, propician la asunción, por parte del lector, de estar ante un viaje realmente realizado que se presenta en forma de relato. En suma, estas marcas actúan en cierta manera como el correlato de la factualidad del texto, de las que se sirven los autores para hacer explícita la autenticidad de su contenido.

La intertextualidad, por su parte, nos alerta sobre las diferentes y variadas familias de relatos que dialogan entre sí, cuyas resonancias nos hablan de tradición e influencias culturales. En muchos casos —yo diría que en todas las épocas - los 'relatos de viajes' establecen un diálogo con obras previas que les sirven de guía o de referente literario. Romero Tobar (2005: 132) lo expresa con acierto: 
[...] los relatos de viaje se nutren tanto de la experiencia real del viajero como de la escritura de relatos anteriores. El relato personal de un viaje entreverá un «yo he visto» con un «yo he leído» de una forma inextricable que, en muchas ocasiones, hace muy difícil al lector el poder separar lo que ha sido experiencia directa del escritor y ecos de las lecturas de otros relatos de viajes anteriores, bien porque éstos han sido tomados como «guía» práctica para el nuevo viajero bien porque la memoria de éste no puede borrar las huellas que le han dejado los textos leídos antes de la redacción del suyo propio. El libro de viaje ofrece fuentes latentes y fuentes patentes o, dicho de otras manera, secuencias de imitación directa y secuencias de imitiación compuesta.

Dejemos apuntado que el solo hecho de dialogar con obras anteriores del mismo tenor — pertenecientes o no al mismo paradigma - supone ya una cierta conciencia de género.

Subrayamos, finalmente, el carácter fronterizo de estos relatos, como otra de las características que saltan a la vista según las consideraciones previas $^{3}$. Habremos de tener en cuenta, no obstante, que las consideraciones en relación con un género tan elusivo y fronterizo no son nítidas y, por tanto, los deslizamientos hacia un terreno u otro se miden (valga el sentido figurado) en términos de grado o de intensidad, o sea, de predominio o, si se quiere, de imposición: desde el punto de vista pragmático, lo factual predomina sobre lo ficcional; desde un punto de vista formal, lo descriptivo se impone a lo narrativo y desde un punto de vista testimonial, lo objetivo prevalece sobre lo subjetivo, pero dependerá de las épocas y los paradigmas en que se inserten los relatos. En cualquier caso, el 'relato de viajes' es siempre «testimonial» lo que implica que el narrador está comprometido con el autor, pues su identidad es plena. Como vemos, las fronteras son lábiles y movedizas. Además, los relatos de viaje también, según los períodos históricos, han compartido fronteras con otras series literarias ${ }^{4}$.

Quiero decir que estas características de los 'relatos de viajes' que los acompañan en su larga trayectoria histórica — con todos sus avatares - hasta el momento actual aluden a una cierta vocación de perdurabilidad que le es intrínseca al género, según trataremos de ver. Como tal, el 'relato de viajes' atraviesa los siglos y sus diferentes períodos engullendo variadas formas literarias y metamorfoseando su condición en moldes cambiantes. Una aproximación a su poética requiere un rastreo de sus huellas en diferentes períodos de la historia si queremos delimitar, aunque sea a grandes rasgos, sus contornos que, en último término, es el objeto que perseguimos. Para ello, trataremos de ahora en adelante fijar la atención en algunos momentos decisivos (hitos) de la evolución del género que nos pueden iluminar sobre su trayectoria.

\footnotetext{
${ }^{3}$ Sobre el relato de viaje como género fronterizo, véase Champeau (2004).

${ }^{4}$ Para una delimitación del género relato de viajes de otros géneros en el Siglo de Oro, puede verse Alburquerque (2005).
} 
Suelen citarse al hablar de la literatura viajera obras como la Odisea de Homero, la Argonáutica de Apolonio de Rodas, la Vida y hazañas de Alejandro de Macedonia o la misma Eneida, todas ellas emparentadas con la literatura de ficción. Y también aquellos textos viajeros más próximos a lo que hoy denominamos ciencia ficción, tales como Las maravillas de Tule de Antonio Diógenes (a través de los resúmenes de Diodoro y Focio), los Relatos verídicos o la Verdadera historia de Luciano (siglo II), divulgados en época romana por Apuleyo.

Ahora bien, en el caso de los 'relatos de viajes' la fuente más directa hay que buscarla en la Historia (siglo v a.C.) de Heródoto y en la Anábasis (siglo IV a.C.) de Jenofonte, en las que pesa el carácter histórico-documental más que cualquier otro. Heródoto y Jenofonte pertenecen a la estirpe de los viajeros reales, que nos hablan de los hechos memorables vistos y oídos en sus viajes y relatados con espíritu de historiador y de reportero avant la lettre, respectivamente. En el caso de Heródoto los viajes discurren por la geografía de los pueblos bárbaros cuya etnografía e historia se nos transmiten con minuciosidad. No es ciertamente protagonista de los acontecimientos narrados - aunque es muy preciso al señalar las fuentes en que se basa - como sí lo fue Jenofonte al transmitirnos su experiencia como soldado mercenario griego reclutado por Ciro. De las tres fuentes referidas (la literatura viajera de ficción, la literatura de viaje de cienciaficción y la literatura de viaje de base historiográfica) los 'relatos de viaje' encuentran su raíz de este lado de la historiografía. Entroncan con un linaje de textos cuyo marchamo literario es indudable. Hérodoto, de hecho, fue siempre conocido en la antigüedad con el epíteto de «gran imitador de Homero» a quien Aristófanes parodió ya en una de sus comedias tempranas, los Acarnienses.

Una primera taxonomía se decanta ya en estas primeras manifestaciones del género. Por un lado, una literatura de viajes ficcional, por otro, una literatura de viajes arraigada en hechos cuyo testimonio nos es transmitido por el autor: son los 'relatos de viajes' cuyo fundamento corresponde al viaje efectivamente llevado a cabo. Estamos fuera de los límites de la ficción. Según esto, los 'relatos de viajes' no son ficción pero sí están dentro de lo literario, del lado de la literatura, aunque en los márgenes de la ficción. Quizá se puede extraer como corolario que la literatura no siempre es ficción, o no solo. Se podría apelar a la autoridad de la Poética de Aristóteles en contra de esta postura, pero bastaría recordar que el Estagirita también argumenta a favor de las obras (léanse tragedias) que recurren a nombres que han existido, ya que — aduce- «Lo sucedido, está claro que es posible, pues no habría sucedido si fuera imposible» ${ }^{5}$. Y también: «Y si en algún caso trata cosas sucedidas, no es menos poeta» ${ }^{6}$. Y más

\footnotetext{
5 Aristóteles, Poética, 1451 b.

$61451 \mathrm{~b}$.
} 
avanzada la Poética podemos leer: «Puesto que el poeta es imitador, lo mismo que un pintor o cualquier otro imaginero, necesariamente imitará siempre de una de las tres manetas posibles; pues o bien representará las cosas como eran o son, o bien como se dice o se cree que son, o bien como deben $\operatorname{ser}^{7} \gg$. Los 'relatos de viajes' se mueven en los límites entre lo literario y lo documental o historiográfico, de ahí que algunos críticos se refieran a su carácter bifronte ${ }^{8}$.

La distinción pertinente, creo yo, no debiera ser la que discrimina entre viajes de ficción y viajes no ficcionales; sino más bien la que diferencia entre 'relato de viajes' (de modalidad factual) y novelas de viaje (de modalidad ficcional) en las que tendrían cabida novelas de aventuras, de ciencia ficción, utopías, etc. Ni mucho menos pertinente aún nos parece aquella distinción que, al diferenciar los viajes no ficcionales (a saber, los viajes científicos o naturalistas) de los ficcionales, divide estos últimos en «viajes imaginarios» - ligados a una estructura ficticia - y «viajes realistas». Según esta clasificación, los 'relatos de viajes' son considerados como «libros de viajes de ficción realista» lo cual supone, desde nuestro punto de vista, un enfoque poco clarificador que tiende, en último término, a considerar el hecho literario exclusivamente del lado de la ficción. El esquema que presentamos más abajo ilustra la posición del 'relato de viajes' (factual/no ficcional/literario, que linda con la historia) en relación con las novelas de viajes (ficcionales/literarias) y sus correspondientes fronteras (todo lo frágiles que se quiera) entre, por un lado, la historia/lo documental y los 'relatos de viaje' y, entre estos últimos y las novelas de viaje, por otro.

\begin{tabular}{|c|l|l|}
\hline \multicolumn{2}{|c|}{ H I S T O R I A } \\
\hline $\begin{array}{c}\text { LITERATURA } \\
\text { DE } \\
\text { VIAJES }\end{array}$ & Factual & Relatos de viajes \\
\cline { 2 - 3 } & Ficcional & Novelas de viajes \\
\hline
\end{tabular}

\section{EDAD MEDIA Y HUMANISMO}

Algunos estudiosos de la literatura viajera en España recalaron en la Edad Media como período especialmente fecundo en obras de este género. A López Estrada se deben trabajos pioneros que abrieron camino en un

\footnotetext{
7 1460b.

${ }^{8}$ Carrizo Rueda (1997).
} 
territorio aún por explorar en los años setenta ${ }^{9}$. El texto de la Embajada a Tamorlán (siglo XV) constituye, en la estela del Libro de las maravillas del mundo de Marco Polo (siglo XIV), el 'relato de viajes' por excelencia, que ha recibido solventes estudios y ediciones ${ }^{10}$. Misiones diplomáticas, de reyes o de pastores de la Iglesia, viajes comerciales, peregrinaciones, son los motivos principales que empujan a los viajeros a sus desplazamientos $\mathrm{y}$ posteriores relatos.

Estamos todavía ante un género en formación. Por eso encontramos algunas crónicas de la baja Edad Media que contienen in nuce algo así como pequeños 'relatos de viaje' que en alguna ocasión he calificado como de microrrelatos, tal es el caso de la Crónica abreviada de España (1482) de Diego de Valera ${ }^{11}$. Decía allí que estas crónicas medievales del siglo XV, de estirpe historiográfica, sugerían ciertos rasgos de modernidad que cristalizarían más adelante en las crónicas de Indias. En primer lugar, la presencia del yo como nuevo argumento de autoridad que se proyectaba en el uso de la primera persona y, en segundo, una voluntad clara de reflejar la realidad tal cual, actitud nada común en los escritores medievales, para quienes la observación de la realidad se limitaba, por lo general, a un uso literario. Estas particularidades (el relato de un viaje realmente efectuado, su testimonio y la descripción objetiva del mismo) propias de los 'relatos de viajes' medievales, tienen mucho que ver con esta tradición de las crónicas de las que vengo hablando.

En algunas partes de la Crónica abreviada de España de Diego de Valera se perciben estos rasgos, sobre todo cuando relata sus viajes en misiones diplomáticas en los que se refiere a países y lugares que ha visitado y que conoce de primera mano. Como ocurrirá también más adelante con las crónicas de Indias, el viajero/narrador se servirá de los recursos de la retórica clásica que, al suministrar esquemas y tópicos compositivos, facilitarán la presentación de las novedades recién descubiertas en las travesías. La relación entre ambos géneros, las crónicas y los 'relatos de viajes',

\footnotetext{
${ }^{9}$ Véase Alburquerque (2006).

${ }^{10}$ Otros muchos libros de viajes de la época se encuadran más propiamente dentro del ámbito de la ficción. Tal es el caso de la Fazienda de Ultramar, de mediados del XII (cuya traducción castellana se sitúa en el primer tercio del XIII), una peculiar guía de peregrinos a Tierra Santa con un sesgo claramente libresco; el Libro del conosçimiento de todos los reinos e tierras e señorios que son por el mundo, escrito hacia 1350 por un franciscano anónimo; el Libro del Infante don Pedro de Portugal, atribuido a Gómez de Santisteban, del que se suele destacar el carácter fabuloso de sus aventuras, de redacción cuatrocentista, cuyas versiones conocidas son del XVI, o las traducciones del Libro de las maravillas de Juan de Mandeville (segunda mitad del XIV). Un caso intermedio lo encontramos en el citado Andanças e viajes por diversas partes del mundo, de Pero Tafur, escrito hacia 1454, caracterizado como relato de aventuras con cierto parentesco con las novelas caballerescas de la época.

${ }^{11}$ Alburquerque (2011).
} 
se manifestará igualmente en que las técnicas compositivas de aquéllas servirán de inspiración a estos ${ }^{12}$. Es claro que algunos 'relatos de viajes' se apropian de ciertos procedimientos de las crónicas.

Aunque en la crónica de Diego de Valera se trata tan solo de un arranque testimonial, supone ya un nuevo modo de autoridad que rivaliza con la de los clásicos. A pesar de que prevalecen el peso de la tradición y las autoridades que legitiman la aparición de lo maravilloso en la crónica, también el «yo», insisto, despunta como autoridad que compite al mismo nivel que la de los clásicos. Esta parte de la crónica de Valera, en que refiere él mismo los lugares que ha conocido, funciona de la misma manera que los 'relatos de viajes' de la Edad Media, caracterizados por ir dejando paso a una geografía más ajustada a la realidad. En otras palabras, la geografía erudita, con toda su carga de maravillas y fábulas, se empieza a ver en cierta manera cuestionada por el peso de «realidad» que aportan los 'relatos de viajes' y las crónicas, como la de Valera, que la incluyen dentro de sí.

Al hacer la descripción geográfica del mundo, por ejemplo, la narración asume a veces la primera persona para hablar de los países y regiones que el autor conoce directamente. A la intención didáctica de esta composición se superpone el afán de protagonismo del autor que proyecta el deseo de ser reconocido por sus hechos, sus hazañas y sus andanzas. Este subrayado testimonial provoca digresiones, desliza el relato hacia lo descriptivo y alienta el uso de figuras retóricas como la evidentia («poner ante los ojos»).

Otro ejemplo cronológicamente anterior de crónica peninsular con incrustaciones de 'relatos de viajes' lo encontramos en la Crònica de Ramón Muntaner (siglo XIV) en la que las vivencias personales se adueñan de gran parte de sus relatos. Habrá que esperar a López de Ayala o a Diego de Valera para encontrar auténticos relatos en los que el 'yo' adquiera un protagonismo tan notable. Gran parte de la crónica se ordena en torno a los viajes que el cronista realizó a lo largo de su ajetreada vida: estancia en París con el séquito de Pedro el Grande, participación activa con las tropas de los almogávares de Roger de Flor por tierras del Levante y, ya al mando de las mismas, recorrido por todo el mediterráneo, permaneciendo siete años en Oriente. En todos sus relatos sobresale la intención de «ver» para «contar». En esas partes que podemos considerar como auténticos 'relatos de viajes' solo se cuenta lo que «vio», la «vera veritat»:

${ }^{12}$ López Estrada (1984: 134-135) señala la coincidencia, en la manera de ofrecer los itinerarios, entre la Embajada a Tamorlán y la Crónica de Juan II. En concreto, el camino del infante don Fernando desde Córdoba a Antequera de la crónica citada se utiliza como patrón narrativo en el texto de la Embajada. 


\begin{abstract}
Muntaner intuye la eficacia persuasiva del yo con que avala su narración y una y otra vez la hace servir. Todavía ahora nos impresiona el efectismo del procedimiento, aunque no veamos en él más que un mañoso ardid estilístico. Para el primer público de la Crònica, el recurso hubo de tener una energía de convicción, un alcance incisivo, que ya no sabemos imaginar. De ordinario, la «historia» no llegaba a las gentes por un cauce tan certificado: tan cierto. En la Crònica encontraban la canción más firme que pudieran desear, porque toda ella venía tramada con frases de confidencia (Fuster, 1970: XIV).
\end{abstract}

Curiosamente, la parte de la crónica dedicada al periplo guerrero por Oriente fue publicada de manera exenta por Blasco Ibáñez en la colección «Prometeo» bajo el título Los almogávares en Bizancio y, ya en los años sesenta, en la editorial Feltrinelli se editó como libro de bolsillo con el título La spedizione di catalani in Oriente, lo que acredita la condición de 'relato de viajes' de algunos de sus pasajes más memorables.

Los dos procedimientos anotados, el subrayado del «yo» como nueva autoridad frente a los clásicos y una voluntad cada vez más acentuada de reflejar la realidad de un modo directo (el autor/narrador es un testigo de excepción), se potenciarán más adelante en algunas de las crónicas de Indias. Quiero fijar mi atención de nuevo ${ }^{13}$ en algunas en concreto, que responden a unas características coincidentes con las del género en cuestión: $E l$ diario de los viajes de Colón, sus Cartas a los Reyes, Las cartas de Relación de Hernán Cortés, los Naufragios de Alvar Núñez Cabeza de Vaca, La historia verdadera de la conquista de la Nueva España de Bernal Díaz del Castillo o la primera parte de La crónica del Perú de Pedro Cieza de León.

Estas crónicas, como recordaba entonces, informan sobre el viaje y transmiten las impresiones recibidas por el descubrimiento del Nuevo Mundo en unos textos de indudable valor literario e incluidos en la mayoría de las historias de la literatura dentro del apartado «Historiadores de Indias». La identidad entre las instancias autor, narrador y personaje surge como uno de los pilares de estos textos. Recordemos cómo Colón en su Diario utiliza reiteradamente la primera persona y se sirve del verbo 'ver' para afianzar la autoría de lo relatado. Alvar Núñez, en el proemio a los Naufragios, justifica la narración de los hechos como testimonios también en primera persona y cierra el proemio con una declaración de autenticidad: «Lo qual yo escriuí con tanta certinidad, que aunque en ella se lean algunas cosas muy nueuas, y para algunos muy diffíciles de creer, pueden sin dubda creerlas; y creer por muy cierto, que antes soy en todo más corto que largo, y bastará para esto auerlo offrescido a Vuestra Majestad por tal» ${ }^{14}$.

Anotemos también que la descripción actúa como elemento configurador del discurso, a lo que se une el hecho de que en estas crónicas de Indias lo descubierto responde a una novedad absoluta. Se podría decir que,

${ }^{13}$ Como ya hice en Alburquerque (2008a).

${ }^{14}$ Apud Alburquerque (2008: 14). 
a través de un análisis detallado de las descripciones, nos asomamos a una dimensión que sobrepasa lo literario, estrictamente hablando, y de la que se ha de dar cuenta con las herramientas lingüísticas entonces al alcance. Los cronistas se encuentran, como sabemos, con una realidad completamente nueva y con unos recursos lógicamente limitados a su formación cultural e intelectual.

Parece evidente que los signos paratextuales, como apuntábamos al comienzo, actúan en estos textos en cierto modo como correlato de su factualidad, hacen explícita la autenticidad de su contenido (así las explicaciones y justificaciones de los prólogos) o se utilizan como marco de los relatos: las cronologías de los diarios de Colón, los epígrafes de los capítulos de los Naufragios, los encabezamientos de las Relaciones de Cortés o, finalmente, las enumeraciones y listas que acompañan a algunas de ellas, como la que se adjunta al final de la primera relación.

También la intertextualidad se refleja en estos textos como rasgo propio del género. Así, los relatos bíblicos, los romances y novelas que formaban parte de la cultura tradicional, las novelas de caballerías o algunos textos jurídicos como Las siete partidas son lecturas que están, consciente o inconscientemente, presentes. La intertextualidad atraviesa las crónicas y constituye uno de las particularidades textuales más interesantes: dice de la manera de ver al otro, de la cultura, de la tradición y de la psicología, que actuarán como filtro para el conocimiento de lo ajeno.

Una exposición más detenida sobre la relación entre las crónicas de Indias y los 'relatos de viajes' nos llevaría a ponderar el alcance formidable de la figura de la descripción ${ }^{15}$. Aquí tan solo quiero recordar la trascendencia que realmente alcanza esta figura, que va más allá de una mera consideración estilística y sugiere aspectos más profundos.

A pesar de la tradición libresca que lastra los relatos de estos descubridores, se puede entrever un paulatino deseo de describir con cierta fidelidad lo observado. Me arriesgaría a afirmar —al hilo de unas reflexiones a otro propósito del gran antropólogo John Howland Rowe (1965)que, gracias a estos viajeros y exploradores del Nuevo Mundo y a la colaboración de humanistas como Nebrija o Mártir de Anglería, se acelera un cambio de paradigma que sintetizo de la siguiente manera: si la Antigüedad clásica consideraba que para comprendernos mejor era necesario estudiarnos mejor a nosotros mismos, con estos 'relatos de viajes' del descubrimiento se inicia la consideración de que para comprendernos mejor a nosotros mismos es necesario estudiar mejor a los otros.

Pasamos por alto ahora los nexos de los 'relatos de viajes' (género fronterizo) con el resto de géneros límitrofes en la época áurea (novela

${ }^{15}$ Ya elaboré un análisis en este sentido en el artículo, aún en prensa, titulado «Crónicas de Indias y relatos de viaje: un mestizaje genérico». 
sentimental, novela bizantina, novela de caballerías y, sobre todo, novela picaresca), lo que nos llevaría muy lejos y a cuya consideración, como ya dije, dediqué un artículo ${ }^{16}$.

\section{DE LA ILUSTRACIÓN AL SIGLO XX}

Durante la primera mitad del siglo XVII tienen lugar dos hechos de enorme importancia para la consolidación del género. En primer lugar se fraguan las condiciones necesarias en Inglaterra del fenómeno que conocemos como el Gran Tour, que alentaba los deseos de conomiento a través de los viajes por Europa. En segundo lugar, la publicación en 1625 del ensayo De los viajes, de Francis Bacon, cuyas consideraciones ejercieron clara influencia en la literatura de viajes estimulada por el Grand Tour. Habrá que esperar a la segunda mitad del siglo XVIII para descubrir otra reflexión sobre la literatura de viajes que contribuya nuevamente a la consolidación del género: el Emilio (1760) de Rousseau contenía el ensayo De los viajes, cuya influencia en Europa no fue menor que la de Bacon. Las aportaciones teóricas con respecto a los viajes (a los 'relatos de viajes' en el sentido en que aquí lo tomamos) alcanzan su máxima consideración en el artículo Voyage de la Enciclopédie de Diderot y D’Alambert, que afianza el viaje como un hecho fundamental en la instrucción de los jóvenes ${ }^{17}$. Señala Arbillaga la influencia de estos textos en la gestación del ensayo que Cadalso incluyó dentro de Los eruditos a la violeta, titulado «Instrucciones dadas por un padre anciano a su hijo que va a emprender sus viajes» (1772), en el que el autor aconseja, entre otras cosas, «anotar cada noche lo observado durante el día y, lo más importante, evitar los prejuicios que el joven traiga de su nación», lo que confirma algunas de las premisas del género comentadas hasta el momento.

El viaje durante la Ilustración se convierte en elemento nuclear en la formación de los jóvenes. La curiosidad por el conocimiento de los otros que se apuntaba en el Renacimiento se consolida ahora como un hecho asumido con absoluta naturalidad. Los viajes científicos y los viajes de formación se erigen en los cauces fundamentales por los que discurren estos relatos. Los primeros, sirvieron para confeccionar grandes colecciones naturalistas cuyo estudio sigue vigente con una gran cantidad de trabajos. Los segundos, entran de lleno dentro de los 'relatos de viajes'.

Sobresalen en esta época en la práctica del género autores como Antonio Ponz y su Viage de España (172-1774), cuyo marcado desequilibrio hacia de lo descriptivo en relación con lo narrativo lo aproxima en cierto

\footnotetext{
${ }^{16}$ Alburquerque (2005).

${ }^{17}$ Vease, para esta cuestión y para todas las relacionadas con el Grand Tour y el 'Viaje a Italia' en España, el documentado trabajo de Arbillaga (2005).
} 
sentido a las guías de viaje. Del mismo o parecido tenor son el Viaje literario a las iglesias de España, de Jaime Villanueva o el resumen del Viaje de Ponz realizado por Conca. Una vez más salta a la vista el carácter fronterizo de estos relatos. Si el texto como el evocado de Ponz se descompensa hasta casi anular el hilo narrativo mínimamente requerible para alcanzar la condición de relato, se alejará, por exceso de descripción, del género como tal. Habría que estudiar con más detalle en qué punto de la frontera genérica se encuentra. El hilo narrativo no puede nunca desaparecer. En tal caso, nos encontraríamos con los «relatos estampa», a los que aludiremos más adelante, que eliminan cualquier atisbo de narración.

Jovellanos o Leandro Fernández de Moratín sobresalen en la práctica del género que, durante el siglo XVIII, alberga las formas de apuntes, diarios, memorias y cartas. Las Cartas de Jovellanos contienen auténticos tesoros en cuanto a los 'relatos de viajes'. De las diez cartas a Antonio Ponz la primera, en concreto, relata un viaje de Madrid a León; la segunda contiene una descripción del convento de San Marcos; la tercera cuenta un viaje de León a Oviedo; la octava parece un fresco de las costumbres y tradiciones folklóricas del pueblo asturiano. Algunos estudiosos dieciochistas consideran que Las diez cartas a Don Antonio Ponz son de lo más valioso de la obra de Jovellanos. Algo similar ocurre con el Diario, aunque en este caso se puede considerar en conjunto como un auténtico 'relato de viajes' que Jovellanos realizó por distintas regiones españolas a modo de Itinerarios en los que anota las incidencias diarias, los lugares visitados y de omni re scibili, según lo aconsejaban las circunstancias. Destaca la minuciosidad de las descripciones, el rigor con que se sitúan los hechos y la sensibilidad con que se dibuja la naturaleza. No en vano se ha destacado su condición de precursor de los 'relatos de viajes' del 98 al comparar el detallismo de sus descripciones paisajísticas con las de maestros como Azorín.

Y lo mismo cabe decir de los 'relatos de viajes' de Leandro Fernández de Moratín, que se cobijan en sus Obras póstumas en forma de apuntes y cartas. Julián Marías (1963: 107) comenta su importancia de manera elocuente:

Con él se fue si no me engaño la posibilidad de que la literatura española del siglo XIX hubiese sido plenamente auténtica, no aquejada por una enfermedad oculta que le impidió ser como la francesa o la inglesa, como había sido en el Siglo de Oro, como había de volver a ser desde el 98 [...] el documento — si vale la expresión- que comprueba esto es precisamente la prosa de este Moratín de sus viajes. Ahí vemos lo que la prosa española pudo ser, lo que tenía que haber sido y no fue. Si hubiera pasado por esas formas, se hubiera ahorrado medio siglo de amaneramiento, de dengues, de tópicos, de afectación, de insinceridad, en suma.

Los 'relatos de viajes' más conocidos y difundidos de la época son las Cartas familiares del padre Andrés. Dirigidas a su hermano Carlos en su 
camino de regreso de Mantua fueron publicadas en primera instancia sin su permiso, aunque el siguiente volumen ya apareció con su consentimiento. En Alemania se hicieron inmediatamente dos traducciones y otra en Italia, lo que da cuenta de su proyección en la época.

Aparte las cartas, diarios, memorias, etc., abundan en el siglo XVIII los viajes a Italia que los intelectuales ilustrados nos han legado en forma de colecciones de 'relatos de viajes' y que son dignos de atención. Entre ellos destacan El Viaje a Italia de José Viera y Clavijo, las propias Cartas familiares desde Italia del padre Andrés o El Viage a Italia de Leandro Fernández de Moratín, que encontrarán continuación en la siguiente centuria.

En suma, el 'relato de viajes' ilustrado se halla inmerso dentro del contexto de formación e instrucción que apunta al docere como su objetivo principal. Se trata de conocer otras culturas, otras gentes, otros pueblos, otras naturalezas —aconsejará Rousseau en el Emilio- El viaje se hace necesario dentro de la cultura ilustrada como medio de educación indispensable y su relato será el precipitado de los conocimientos acumulados a través de la experiencia viajera. Las formas que asume el 'relato de viajes' ya no tienen que ver principalmente con las relaciones, crónicas o embajadas de los siglos anteriores, sino con las memorias, los apuntes, las cartas, los diarios, la prensa. El género se metamorfosea en otros moldes distintos de los de la Edad Media y el Renacimiento, manteniendo sus mecanismos básicos: se trata de viajes reales posteriormente narrados con una clara voluntad descriptiva y un arraigado sentido de la testimonialidad como argumento del «yo» que se instaura de modo natural en su maquinaria narrativa.

El sesgo romántico dejará su impronta en este género al convertir la voz del autor/narrador en una instancia decisiva. Como ha señalado acertadamente Huenen (2008: 40), durante el siglo XIX la literatura de viajes experimentó importantes cambios de forma y contenido «debido a una inversión en su relación con la literatura a secas: la narrativa pasa de ser una secuela del viaje a convertirse en su justificación». El viaje se instala de pleno derecho dentro de los límites de la literatura y los viajeros se vuelven cada vez más intercambiables con la figura del escritor.

Es claro -insistimos - que la literatura de viajes ficcional, tan abundante en el período romántico, no comparte el marco genérico del 'relato de viajes' tal cual lo hemos propuesto. Bien es cierto que comparte procedimientos - como no podía ser de otra manera- pero se enmarca del lado de la ficción. No es infrecuente, en sentido contrario, el pseudo-relato de viaje o viaje artístico-literario, modalidad romántica donde la descripción se impone de tal manera al componente narrativo que neutraliza su condición misma de relato. La Historia de los Templos de España (cuyo primer y único tomo es el referido a Toledo) de Bécquer o los escritos que Galdós también dedicó a la ciudad del Tajo, pertenecerían a este tipo 
de obras «inmóviles», más próximas a los cuadros de costumbres o «relatos-estampa» que a otra $\operatorname{cosa}^{18}$.

El 'relato de viajes', recordamos, contiene un sujeto de doble experiencia: el viaje y la escritura. Es un sujeto de doble instancia: sujeto viajero, individual e irreemplazable que, además, escribe esa experiencia. $\mathrm{Su}$ estatuto ficcional es ciertamente peculiar. Se trata del hombre de carne y hueso, sin mediación de ningún otro tipo de voz imaginaria. El lector suspende su capacidad de incredulidad y acepta como no ficcional lo que el sujeto relata, aunque a veces recurra a lo ficcional (sin menoscabo de la credibilidad), pero siempre con el fin de garantizar la verosimilitud. La identidad plena narrador/autor se proyecta en el lector en forma de un compromiso similar al que se le exige mediante el «pacto autobiográfico».

El caso es que el género goza de una vitalidad extraordinaria durante el siglo XIX y afianza la figura del viajero que se identifica cada vez más con la del escritor. Así como en el siglo anterior el viaje formaba parte de la formación del individuo que se veía en cierto modo apremiado a su realización, ahora el relato mismo se convierte - como recuerda Le Huenen- en condición primera del viaje, en vez de ser el resultado o una de sus posibles consecuencias ${ }^{19}$.

El 'relato de viajes' se convierte además, según el mismo autor (2008: 43), en un género al que se consagra una parte de los escritores, al menos en Francia: «La entrada en la literatura del relato de viajes es así la ocasión que tiene la literatura de reivindicar la autonomía de su espacio significante y la de sus prácticas, así como de los dispositivos que le son propios en la producción del sentido».

La tipología, como vemos, es variada y los autores y obras tan numerosos en España como en el resto de Europa. El género está plenamente arraigado en el siglo XIX y el interés por este tipo de obras es creciente. La lista es inmensa. Por aludir solo a los más conocidos cito como botón de muestra los siguientes: el duque de Rivas (Viaje al Vesubio o el Viaje a las ruinas de Pesto), Galdós (Viaje a Italia, Recuerdos de Italia, Cuarenta leguas por Cantabria, etc.), Amós de Escalante (Del Ebro al Tiber), Pedro Antonio de Alarcón (De Madrid a Nápoles, La Alpujarra), Mesonero Romanos (Recuerdos de viaje por Fancia y Bélgica), Emilia Pardo Bazán (Por Francia y por Alemania), etc., etc. Vicente Blasco Ibáñez y Valera sobresalen por las crónicas periodísticas de los viajes agavilladas más tarde en forma de relatos. Así ocurre con el primero en París (Impresiones de un emigrado) 1890-1891 y En el país del arte. (Tres meses en Italia), aunque no sea éste el caso de La vuelta al mundo de un novelista, una de las obras mejor valoradas del autor.

\footnotetext{
18 Véase Rubio Jiménez (1992).

19 Le Huenen (2008: 43).
} 
Las Cartas de Rusia de Valera, por su parte, son un ejemplo memorable de 'relato de viajes' en el que, aparte del molde epistolar en el que destacó su autor con verdadera maestría, se evidencia el proceso de intertextualidad, una de las características citadas al comienzo como propias del género. Para Romero Tobar (2005: 150) las Cartas de Rusia de Valera están en relación con las cartas escritas unos años antes por el marqués de Custine: «Pero el lector de ambos viajes no puede permanecer impasible ante lo que, legítimamente, ha de ser leído como un caso más del funcionamiento de la reescritura en los libros de viaje».

Muchos de estos relatos arriba citados abrirán el camino para la literatura viajera del 98, que encontrará en algunos de estos autores —pienso en Alarcón, por ejemplo- un auténtico precursor. Arbillaga (2005: 375) recuerda cómo De Madrid a Nápoles (1861) fue el libro viaje más leído en España en el siglo XIX: «Resulta primordial para este estudio que la obra de viaje más leída en la España del siglo XIX fuera un libro de viajes por Italia, lo que no dejará de sorprender a la poco informada crítica europea que todavía desconoce la aportación española a esta tradición, o que acaso la conoce y la excluye injustificadamente». Los artículos publicados en la prensa periódica y recogidos luego de manera exenta fueron el origen de muchos de los 'relatos de viajes' de la época. El periodismo y la literatura tuvieron en el siglo XIX uno de sus puntos de encuentro precisamente en la literatura viática y Alarcón no escapa a este hecho ${ }^{20}$.

No es posible pasar al siglo XX sin reparar en la influencia de los 'relatos de viajes' de la generación del 98. Está todavía por hacer, que yo sepa, un estudio de conjunto que analice el desarrollo y la importancia del género en la producción noventayochista y posterior. "Las notas de andar y ver. Viajes, gentes y países» de Ortega y Gasset marcaron la pauta teórica de gran parte de la escritura viajera de la primera mitad del siglo $\mathrm{XX}$ español.

Para Ortega, la unión de hombre y naturaleza a través del paisaje conforma una manera de ver la realidad en la que ambas instancias (el hombre y el medio) actúan metonímicamente. Los 'relatos de viajes' de Unamuno, Baroja o Azorín no se entienden bien sin esta teoría del paisaje apenas esbozada. Hablar del hombre implica referirse necesariamente al medio y viceversa ${ }^{21}$. El hombre es su paisaje y éste, sin aquel, es materia inerte, deshumanizada. El yo y la circunstancia orteguiana asumen una dimensión de un enorme calado en los 'relatos de viajes' del 98 que será singularmente incorporada por la brillante obra viajera de Cela. La figura

\footnotetext{
${ }^{20}$ Un repaso pormenorizado a través de la modalidad del 'relato de viaje' a Italia puede consultarse en la obra citada de Arbillaga (2005), lo que da cuenta del vigor que había adquirido el género a lo largo del siglo XIX.

${ }^{21}$ El tema es abordado con más detalle por Pozuelo Yvancos (1991: 22).
} 
de Ciro Bayo destaca en este panorama al actuar de gozne, recordemos su Peregrino entretenido (viaje romancesco) publicado en 1910, entre el 98 y la obra recién aludida de Camilo José Cela.

La gran contribución de Ciro Bayo al género reside en la incorporación de lo «romancesco» a un relato demasiado ceñido a lo documental. Bayo, sin renunciar a los elementos esenciales del género, lo acerca a las fronteras de lo novelesco al apropiarse de algunos de sus recursos y al haber transformado en ficticios determinados elementos de la narración, sin menoscabo de su modalidad factual. El género ha ensanchado sus límites disponiéndose para una renovación que conocerá su máximo aprovechamiento en la literatura viajera de Cela y en toda la tradición posterior ${ }^{22}$. De nuevo surge el carácte lábil de estos relatos al poder deslizarse hacia lo ficticio sin perder su condición factual. A nadie le extraña que Bayo o Cela sublimen personajes u objetos o que incluso en ocasiones los inventen. Seguimos en el plano factual (el viaje realmente llevado a cabo) que incorpora lo ficcional como un ingrediente más.

No podemos pasar por alto el género de los 'relatos de viajes' sociales de la España de postguerra. Juan Goytisolo (Campos de Nijar), Armando López Salinas y Ferres (Caminando por las Urdes), Antonio Ferres (Tierra de Olivos) o Grosso y López Salinas (Por el río abajo), son algunos de los nombres imprescindibles dentro del género, que aportó un significativo número de obras.

El listado de autores contemporáneos de 'relatos de viajes' es inmenso: Javier Reverte ${ }^{23}$, Manuel Leguineche, Julio Llamazares, Juan Pedro Aparicio, José María Merino, Manuel de Lope, Luis Mateo Díez, Antonio Muñoz Molina, Lorenzo Silva, Alfonso Armada, Rafael Argullo, Jordi Carrión, suponen tan solo una pequeña parte de viajeros que nos han transmitido sus relatos ${ }^{24}$. Champeau (2004) ofrece una tipología del género desde principios del siglo XX hasta autores como Luis Mateo Díez o Alfonso Armada basada en la diversidad con respecto al viaje único consagrado por autores como Cela y mantenido a lo largo del siglo pasado. Al hilo de su rastreo aporta unas conclusiones muy acordes con nuestro propósito: «Una mirada panorámica sobre más de un siglo de literatura viajera comprueba una evolución en el sentido de una mayor trabazón de las obras, de una mayor homogeneidad y depuración, de una supeditación de los componentes documentales y ensayísticos a la narración y de la casi desaparición de los rasgos de escritura propios de los discursos del saber».

\footnotetext{
${ }^{22}$ Véase Alburquerque (2008).

${ }^{23}$ Hay incluso un volumen editado por Julio Peñate (2005) dedicado a la obra de viajes de este autor.

${ }^{24}$ Un interesante seguimiento de autores y relatos de viajes de las últimas décadas del siglo XX puede verse en María Rubio (2004).
} 
La literatura viajera absorbe también en los últimos años aspectos vinculados con la postmodernidad y el mundo globalizado. En este contexto, abundan los 'metarrelatos de viajes'. Jordi Carrión (2007: 33) da las claves de los derroteros por los que transita el género 'relato de viajes' postmoderno:

El metaviajero de nuestra postmodernidad última no va, regresa (así hay que entender los libros del cambio de siglo de W.G. Sebald, Juan Goytisolo o Cees Nooteboom), o cuando va por primera vez, es tal la información previa acumulada, que hay en su experiencia menos conocimiento que reconocimiento (los reportajes de Martín Caparrós o de David Foster Wallace, por ejemplo). El viaje se da en paralelo al de los viajeros precedentes, como ha ocrurrido siempre; pero por vez primera el marco semiótico está sobresaturado de textos y de lenguajes, de modo que la distancia irónica, tanto respecto a los precursores como a la misma posibilidad de entender la realidad que se visita, se convierte en una premisa inevitable de la inteligencia en movimiento. Los filtros se problematizan. Se explicitan el testimonio, la lectura, el intérprete, la lengua franca (el inglés, por lo general) o los factores del contexto. En el fondo, como horizonte de todo el arte de viaje de nuestra época, se muestra de un modo u otro la dificultad añadida por la globalización.

\section{CONCLUSIÓN}

Los tres rasgos nucleares señalados al inicio de la exposición pueden esquematizarse en tres binomios a los que me he referido en trabajos anteriores $^{25}$ : factual/ficcional, descriptivo/narrativo y objetivo/subjetivo. Según lo dicho, y con respecto al primer binomio, si la balanza textual se inclina del lado de lo ficcional (dependiendo del grado en que lo haga), nos alejamos del género propiamente dicho (es el caso de las novelas de viajes en forma de aventuras, de ciencia ficción, utopías, etc.). Si en la pareja descriptivo/narrativo el segundo término del par domina sobre el primero también nos distanciamos de lo descriptivo, uno de los puntales de estos relatos. Por el contrario, si lo descriptivo invade completamente la escena, nos encontramos con los casos ya evocados (Viajes de Ponz en el siglo XVIII, relatos estampa del siglo XIX) en que por exceso de lo descriptivo nos apartamos del esquema genérico (las guías de viaje ejemplificarían este caso extremo). En cuanto al tercer binomio, objetivo/subjetivo (vinculado muchas veces a una determinada carga ideológica), sucede algo parecido: si se potencia lo subjetivo por encima de lo objetivo nos alejamos paulatinamente del modelo. En la medida en que el relato se convierte en pura subjetividad se sale del marco genérico. Otra cosa distinta es que lo subjetivo prevalezca sin merma de los elementos testimoniales (como sucede, por ejemplo, con los relatos de viaje ensayísticos de los escritores del 98).

\footnotetext{
${ }^{25}$ Véase Alburquerque (2009).
} 
Es decir, la hipertrofia de los aspectos ficcionales a expensas de los factuales, de lo subjetivo a expensas de lo objetivo y de lo descriptivo a expensas de lo narrativo, enmarcarían por defecto (de lo factual y de lo objetivo) y por exceso (de lo descriptivo) las fronteras del género. Estos binomios, junto con las precisiones hechas sobre la importancia de los aspectos paratextuales e intertextuales, pueden facilitar la clasificación del variado arco de obras que caben dentro del género 'relato de viajes'.

Concluyo volviendo al principio. Sigo pensando que la definición que expuse en aquel artículo al que aludí al comienzo puede básicamente seguir sirviendo con algunas precisiones que ahora van en cursiva (Alburquerque, 2006: 86):

El género [de los relatos de viaje] consiste en un discurso factual que se modula con motivo de un viaje (con sus correspondientes marcas de itinerario, cronología y lugares) y cuya narración queda subordinada a la intención descriptiva, que dota al género de una cierta dosis de realismo. Suele adoptar la primera persona (a veces, la tercera), que nos remite siempre a la figura del autor como testigo de los hechos y aparece acompañada de ciertas figuras literarias que, no siendo exclusivas del género, sí al menos lo determinan. [...] Las marcas de paratextualidad (como correlato de la modalidad factual) y de intertextualidad son propias, aunque lógicamente tampoco exclusivas, de estos 'relatos de viajes'. Está fuera de todo duda que los límites de este género no cuentan con perfiles nítidos. Hay que señalar, sin embargo que, en sus manifestaciones sucesivas, las fronteras del género adquieren contornos más definidos. $\mathrm{O}$ sea, aunque sus orígenes se nos presentan como más evanescentes, se pueden proponer características que lo distinguen de los otros géneros limítrofes y que lo fueron asentando con el paso del tiempo. Por lo demás, es lo habitual. Ningún género empezó su andadura como tal. Solo al cabo del tiempo estamos en condiciones de poder bautizar algo que ya tiene una sólida trayectoria.

\section{REFERENCIAS BIBLIOGRÁFICAS}

ALBURQUERQUE-GARCÍA, Luis (2011). «La Crónica abreviada de España (1482) de Diego de Valera y el desarrollo del género 'relato de viaje', Hipania Felix, Ignacio Arellano (ed.), Viajes y viajeros en el Siglo de Oro, II, pp. 25-37.

- . (2009). "Algunas notas sobre la consolidación de los relatos de viaje como género literario», en Ignacio Arellano, Víctor García Ruiz y Carmen Saralegui (eds.). Ars bene docendi. Homenaje al profesor Kurt Spang. Pamplona: Eunsa.

-. (2008a). «El peregrino entretenido de Ciro Bayo y el relato de viaje a principios del siglo XX», en Julio Peñate Rivero y Francisco Uzcanga Meinecke (eds.). El viaje en la literatura hispánica: De Juan Valera a Sergio Pitol. Madrid: Verbum, pp. 145-160.

-. (2008b). «Apuntes sobre crónicas de Indias y relatos de viajes», Letras (Buenos Aires), 57-58, pp. 11-22.

-. (2006). «Los libros de viajes como género literario», en Manuel Lucena Giraldo y Juan Pimentel (eds.), Diez estudios sobre literatura de viajes. Madrid: CSIC, pp. 67-87.

- . (2005). «Consideraciones acerca del género 'relato de viajes' en la literatura del Siglo de Oro», en Carlos Mata y Miguel Zugasti (eds.), Actas del congreso «El Siglo de Oro en el nuevo milenio». Pamplona, Eunsa. 
ARBILlAGA, Idoia (2005). Estética y teoría del libro de viaje. El 'viaje a Italia' en España. Málaga: Anejo LV de Analecta Malacitana.

ARISTÓTELES. Poética, ed. trilingüe de Valentín García Yebra. Madrid: Gredos, 1974.

CARRIÓN, Jordi (2007). «Del viaje: penúltimas tendencias», Quimera, Jordi Carrión (coord.), Metaviajeros, 284/5, pp. 32-35.

CARRIZO RUEDA, Sofía (1977). Poética del relato de viajes. Kassel: Reichenberger.

CHAMPEAU, Geneviève (2004). «El relato de viaje, un género fronterizo», en Geneviève Champeau (ed.), Relatos de viajes contemporáneos por España y Portugal. Madrid: Verbum, pp. 15-31.

DORRA, Raúl (1983). «La actividad descriptiva de la narración», en Miguel Ángel Garrido Gallardo (ed.), Teoría semiótica. Lenguajes y textos hispánicos, vol. 1, pp. 509-516.

FUSTER, Joan (1970). «Introducción» en la Crònica de Ramón Muntaner. Madrid: Alianza Editorial.

GARCÍA BARRIENTOS, José-Luis (1988). Las figuras retóricas. Madrid: Arco/Libros.

LE HUENEN, Roland (2008). «El relato de viajes: La entrada en la literatura», Quimera, Patricia Almarcegui (coord.), Viajeros del siglo XIX. Del libro de viaje a la literatura de viaje, 298, pp. 40-47.

MARÍAS, Julián (1963). «España y Europa en Moratín», en Los españoles, Madrid: Revista de Occidente.

PEÑATE RIVERO, Julio (ed.) (2005). Leer el viaje. Estudios sobre la obra de Javier Reverte. Madrid: Visor.

POZUELO YVANCOS, José María (1991). «Introducción», en Viaje a la Alcarria. Madrid: Espasa Calpe, pp. 9-53.

ROMERO TOBAR, Leonardo (2005). «La reescritura en los libros de viaje: las Cartas de Rusia de Juan Valera», en Leonardo Romero Tobar y Patricia Almarcegui Elduayen (coords.). Los libros de viaje: realidad vivida y género literario. Madrid: Akal, pp. 129-150.

ROWE, John Holwland (1965). «The Renaissance Foundations of Antropology», American Anthropologist, 67, pp. 1-20

RUBIO JIMÉNEZ, Jesús (1992). «El viaje artístico-literario: una modalidad literaria romántica», Romance Quarterly, 39, pp. 21-31.

RUBIO MARTÍN, María (2004). «Los libros de viajes en la España de las Autonomías», Quimera, Geneviève Champeau (coord.), Viajar para contarlo, 246-247, pp. 82-87.

Fecha de recepción: 19 de enero de 2010

Fecha de aceptación: 8 de septiembre de 2010 